\title{
Produção e qualidade de morangueiro sob diferentes concentrações de calda bordalesa, sulfocálcica e biofertilizante supermagro
}

\author{
Strawberry production and quality under different concentrations \\ of bordeaux mixture, lime sulfur and the biofertilizer supermagro
}

\author{
Sérgio Miguel Mazaro $^{1 *}$; Marindia Caprini Mangnabosco²; \\ Idemir Citadin ${ }^{3}$; Dalva Paulus ${ }^{1}$; Alfredo de Gouvea ${ }^{4}$
}

\begin{abstract}
Resumo
O trabalho teve como objetivo avaliar o comportamento agronômico e as alterações físico-químicas de morangueiros em sistema de cultivo orgânico em função da aplicação de diferentes concentrações de calda bordalesa, calda sulfocálcica e biofertilizante supermagro. O primeiro experimento foi realizado em 2007, com a cultivar Camarosa, em um esquema fatorial 3 x 5, sendo: o fator A constituído pela calda bordalesa, calda sulfocácica e biofertilizante supermagro; o fator B representado pelas concentrações de 0,$5 ; 1,0 ; 2,0 ; 4,0$ e a testemunha. No segundo experimento, em 2008, os tratamentos foram um fatorial $5 \times 3$, sendo: o fator A representado pelas caldas (calda bordalesa a $1 \%$; calda sulfocálcica a $1 \%$; biofertilizante supermagro a 4\%, alternância de aplicação de caldas nas mesmas concentrações e a testemunha); o fator B pelas cultivares (Camarosa, Camino Real e Albion). As caldas bordalesa e sulfocálcica, bem como o biofertilizante supermagro interferem positivamente no número de frutos, massa média e produção do morangueiro. Concentrações acima de $1,0 \%$ de calda bordalesa e sulfocálcica causam manchamento dos frutos, limitando sua utilização. O supermagro não apresenta restrição, sendo que as melhores respostas agronômicas foram observadas nas maiores concentrações testadas. A aplicação das caldas e do supermagro interferem no controle de doenças com redução da severidade da mancha-de-micosferela na cultivar Camarosa.
\end{abstract}

Palavras-chave: Cultivo orgânico, caldas, biofertilizantes

\begin{abstract}
The objective of this study was to evaluate the agronomic performance and physical-chemical changes of strawberry in organic cropping system according to the application of different concentrations of bordeaux mixture, lime sulfur and fertilizer supermagro. The first experiment was conducted in 2007, with cultivar Camarosa, with a 3 x 5 mixed factorial, been: the factor A constituted of Bordeaux mixture, lime sulfur and fertilizer supermagro; the factor B represented by concentrations of $0.5,1.0,2.0,4.0 \%$ and the control. In the second experiment, in 2008, the treatments were a 5 x 3 factorial design, been: the first factor represented by mixture (Bordeaux mixture at $1 \%$; lime sulfur at $1 \%$; biofertilizer supermagro $4 \%$; alternating application of this mixtures at the same concentrations; and control); and the factor B by cultivars (Camarosa, Camino Real, and Albion). The bordeaux mixture, lime sulfur and fertilizer
\end{abstract}

${ }^{1}$ Eng $^{\text {os }}$ Agr $^{\text {os }}$ Profs. Drs. do Curso de Agronomia, Universidade Tecnológica Federal do Paraná, UTFPR, Câmpus Dois Vizinhos, PR. E-mail: sergio@utfpr.edu.br; dalvapaulus@utfpr.edu.br

${ }^{2}$ Eng $^{\mathrm{a}}$. Agr ${ }^{\mathrm{a}}$, M.e Curso de Pós-graduação em Agronomia, UTFPR, Câmpus Pato Branco, Pato Branco, PR. E-mail: marindiacm@ yahoo.com.br

${ }^{3}$ Eng $^{\circ}$ Agr $^{\circ}$, Dr. Prof. do Curso de Agronomia, UTFPR, Câmpus Pato Branco, Pato Branco, PR. E-mail: idemir@utfpr.edu.br

${ }^{4}$ Licenciado em Ciências Agrícolas, Prof. Dr. do Curso de Agronomia, UTFPR, Câmpus Dois Vizinhos, PR. E-mail: alfredo@ utfpr.edu.br

* Autor para correspondência 
supermagro interferes positively in the number of fruits, average weight and yield of strawberry. Concentrations above $1.0 \%$ of Bordeaux mixture and lime sulfur cause staining of the fruit, limiting its use. The supermagro show no restriction being that the best agronomic responses were observed at higher concentrations tested. The application of Bordeaux mixture, lime sulfur and supermagro interfere with disease control with reduced severity of the stain micosferela in the cultivar Camarosa.

Key words: Organic farming, syrups and biofertilizers

\section{Introdução}

No Brasil a cultura do morangueiro desempenha um importante papel sócio econômico nas regiões Sul e Sudeste, tanto para o consumo in natura quanto para a indústria alimentícia, sendo uma importante alternativa de renda para agricultura familiar.

Apesar desse potencial, a cultura apresenta alguns fatores limitantes, sendo o principal sua susceptibilidade a várias doenças e pragas, que podem acarretar grandes perdas de produção e qualidade. Estes fatores são consideravelmente limitantes à expansão do cultivo orgânico da cultura. Entre as medidas que visam aperfeiçoar o cultivo orgânico, está o emprego de caldas fitoprotetoras, sendo muito utilizadas as caldas bordalesa e sulfocálcica, além do biofertilizante supermagro. Essas caldas vêm sendo usadas na produção orgânica com o objetivo de complementar a nutrição das plantas, controlar doenças e reduzir a população de pragas (VENZON et al., 2006).

A calda bordalesa é constituída da mistura de cal virgem e sulfato de cobre, apresenta ação fungicida e bactericida, sendo aplicada de forma preventiva no controle de doenças. Possui grande utilização no cultivo da videira, embora persistam algumas dúvidas, como utilização em diferentes cultivares, acumulação de cobre no solo e na planta pelo uso contínuo, bem como restrições por doses elevadas, sendo estas extremamente tóxicas, causando sintomas como clorose, necrose entre outros danos (PERUCH; BRUNA, 2008).

Acalda sulfocálcica é um produto deuso frequente na agricultura orgânica e possui ação fungicida, inseticida e acaricida, sendo utilizada também como fertilizante foliar. É um sulfurado inorgânico que possui como princípio ativo o polissulfeto de cálcio, obtido pela dissolução de enxofre em pó e cal virgem ou hidratada (ANDRADE; PATARRO; OLIVEIRA, 2011).

O biofertilizante supermagro é proveniente da fermentação anaeróbica em meio líquido da matéria orgânica animal ou vegetal, resultando em um resíduo aquoso e sendo utilizado como adubo foliar, defensivo natural, podendo complementar a adubação orgânica do solo por fornecer micronutrientes essenciais ao metabolismo, crescimento e produção de plantas. O biofertilizante é um meio de crescimento de bactérias benéficas inibindo o desenvolvimento de fungos e bactérias que causam doenças nas plantas, aumentando a resistência contra insetos e ácaros (MESQUITA et al., 2007). Tal biofertilizante foi desenvolvido pelo Centro de Agricultura Ecológica (CAE), no município de Ipê - Rio Grande do Sul, com objetivos de utilização para as culturas da maçã, pêssego, uva, tomate, batata e hortaliças em geral.

Desta maneira, os estudos sobre a utilização da caldabordalesa, calda sulfocálcica e dobiofertilizante supermagro na cultura do morangueiro são de grande importância cientifica e sócio-econômica, pois vêm contribuir para o desenvolvimento de tecnologias focadas na produção de alimentos saudáveis e com redução de custos com agrotóxicos.

O objetivo do trabalho foi avaliar o comportamento agronômico de morangueiros e as alterações físico-químicas de morangos em sistema de cultivo orgânico em função da aplicação de diferentes concentrações de calda bordalesa, calda sulfocálcica e biofertilizante supermagro. 


\section{Material e Métodos}

Os experimentos foram conduzidos no ano de 2007 e 2008 na Universidade Tecnológica Federal do Paraná (UTFPR), Câmpus Dois Vizinhos - PR, situada a $25^{\circ} 42^{\prime} \mathrm{S}$ e $53^{\circ} 03^{\prime} \mathrm{W}$, a 519 metros de altitude. O solo local é do tipo Latossolo Vermelho Distroférrico Típico, com terreno apresentando a declividade média em torno de 3\%. O sistema de condução foi em campo, cobertura de solo com acícula de pinus e irrigação por aspersão, no espaçamento de $0,30 \times 0,30 \mathrm{~m}$ entre plantas e quatro fileiras por canteiro.

O primeiro experimento, realizado em 2007, foi um fatorial misto $3 \times 5$, sendo o fator $\mathrm{A}$ constituído pela calda bordalesa, calda sulfocácica e biofertilizante supermagro e o fator B representado pelas concentrações de $0,5,1,0,2,0,4,0 \%$ e a testemunha em que se aplicou água. A cultivar utilizada foi a Camarosa. No segundo experimento, no ano de 2008, adotou-se um esquema fatorial $5 \times 3$, sendo o fator A representado pelas caldas (calda bordalesa a $1 \%$; calda sulfocálcica a $1 \%$; biofertilizante supermagro a 4\%; alternância de aplicação de caldas nas mesmas concentrações e a testemunha) e o fator B pelas cultivares (Camarosa, Camino Real e Albion). Para ambos os experimentos utilizou-se 16 plantas por parcela em quatro repetições. As aplicações dos tratamentos foram realizadas a cada 7 dias.

A calda sulfocálcica foi adquirida no comércio local e oriunda de produção industrial, com uma concentração inicial de $32^{\circ}$ Baumé. A calda bordalesa e o biofertilizante supermagro foram preparados na UTFPR - Câmpus Dois Vizinhos seguindo as orientações de Burg e Mayer (2002).

Após cada colheita, os frutos foram transportados até o laboratório de bioquímica e fitossanidade da UTFPR - Câmpus Dois Vizinhos, onde foram feitas as seguintes avaliações: produtividade média por planta, obtida somando-se a massa dos frutos de todas as colheitas, dividindo-se pelo número de plantas da parcela; massa média de frutos por planta, obtida dividindo-se a massa total dos frutos pelo número total de frutos por planta; acidez titulável, determinada em amostra de $10 \mathrm{~mL}$ de suco dos frutos, extraído através de maceração em almofariz, sendo essa amostra diluída em $100 \mathrm{~mL}$ de água destilada e titulada com uma solução de hidróxido de sódio a $0,1 \mathrm{~N}$ até $\mathrm{pH} 8,1$; sólidos solúveis totais, determinados por refratômetria manual, com posterior correção do efeito da temperatura e o resultado expresso em ${ }^{\circ}$ Brix. Com relação aos danos aos frutos considerou-se a presença e ausência e percentual danificado, considerando fruto danificado aquele que apresentava características anormais de coloração (tingimento do fruto).

Avaliaram-se as seguintes doenças: mancha-demicosferela, mancha-de-dendrofoma e antracnose. As avaliações de incidência foram realizadas a cada 20 dias. Efetuou-se a contagem do número de folhas com sintomas das doenças, considerandose as quatro plantas centrais de cada parcela, e a incidência definida pelo percentual de folhas atacadas em relação ao total de folhas das plantas avaliadas. Para avaliação da antracnose, foi efetuada a determinação da incidência de sintomas típicos do ataque do patógeno, caracterizado pela necrose do pecíolo, das flores e frutos jovens, deformações em frutos verdes e manchas deprimidas nos frutos maduros (TANAKA; PASSOS, 2002). Foram realizadas contagens do número de estruturas com sintomas da doença (pecíolos, flores e frutos), considerando-se as quatro plantas centrais de cada parcela, e a incidência definida pelo percentual total de pecíolos, flores e frutos atacadas em relação ao total das plantas avaliadas. Para mancha-demicosferela, além da incidência, foi realizada avaliação da severidade, aplicando-se a escala diagramática proposta por Mazaro et al. (2006).

Com base nos dados obtidos foi determinada a área abaixo da curva de progresso da incidência e severidade da doença através da metodologia proposta por Campbell e Madden (1990), pela seguinte fórmula: 


$$
A A C P D=\sum_{i}^{n-1}\left(\frac{y_{i}+y_{i+1}}{2}\right)\left(t_{i+1}-t_{i}\right)
$$

onde $\mathrm{y}_{\mathrm{i}}=$ incidência ou severidade na época da avaliação i e $t_{i}=$ tempo da avaliação $i$.

Os resultados obtidos foram submetidos à análise de variância e comparação de médias pelo teste de Tukey $(P \leq 0,05)$ ou regressão pelo programa SISVAR.

\section{Resultados e Discussão}

\section{Experimento 1 - ano 2007}

A utilização de calda bordalesa e sulfocálcica, e do biofertilizante supermagro contribuíram para o aumento da produção, massa médiaenúmero de frutos por planta no morangueiro cv. Camarosa (Figuras 1A, 1B e 1C). A máxima eficiência técnica foi obtida com, aproximadamente, $1,60 \%$ e $1,70 \%$ para calda bordalesa e calda sulfocálcica, respectivamente. Acima dessas concentrações ocorreu decréscimo do número de frutos e consequentemente na produção. Isso se deve ao possível efeito fitotóxico, provocados por concentrações elevadas e a frequência de aplicações dessas caldas. Góes, Martins e Reis (2004), quando aplicaram produtos cúpricos em goiabeira, não verificaram sintomas de fitotoxicidade em frutos de tamanho inferior a 15 $\mathrm{mm}$ de diâmetro. Contrariamente, estes produtos, quando aplicados isoladamente em frutos entre 25 a $35 \mathrm{~mm}$ de diâmetro, causaram sintomas severos de fitotoxicidade, todavia com resultados positivos no controle de ferrugem da goiabeira. Por outro lado, a aplicação de calda bordalesa em concentrações de 0,1 a $0,8 \%$ não influenciaram na produtividade de videira cv. Goethe (PERUCH; BRUNA, 2008).

Nos tratamentos com o biofertilizante supermagro ocorreu comportamento linear crescente para massa média de frutos (1B), no número de frutos por planta (1C) e consequentemente na produção por planta (1A) até a concentração de $4 \%$ (Figura 1A), e não apresentou efeito fitotóxico aos frutos. Isso demonstra a importância da aplicação do mesmo na cultura do morangueiro, fato também observado na cultura do mamoeiro por Mesquita et al. (2007). O efeito positivo do biofertilizante supermagro no aumento da massa média de frutos também foi observado por Rodrigues et al. (2009), em maracujazeiro-amarelo.

O emprego das caldas e do biofertilizante supermagro não alterou os teores de acidez titulável e de sólidos solúveis totais nos frutos, sendo que os valores obtidos estiveram dentro dos padrões de normalidade para a cultivar camarosa,variarando de 10 a 10,2 g de ácido cítrico/100 $\mathrm{mL}$ e de 6,1 a 6,4 ${ }^{\circ}$ Brix para acidez e sólidos solúveis totais, respectivamente. A acidez é um dos componentes responsáveis pelo sabor e aroma e a relação açúcares/acidez é geralmente utilizada como índice de qualidade e de aceitabilidade de frutas pelo consumidor. No processo natural de maturação dos frutos ocorre a perda da acidez devido a utilização dos ácidos orgânicos, principalmente cítrico e málico em morangos, como substrato no processo respiratório via ciclo de Krebs (MAZARO et al., 2008).

$\mathrm{Na}$ avaliação de danos nos frutos, observou-se que, nas concentrações acima de 1,0\% de calda bordalesa e sulfocálcica, os frutos apresentavam-se manchados pelas caldas (tingidos), sendo esse um fator limitante na utilização de concentrações acima desse valor. Já para o biofertizante supermagro esse dano não foi observado. Os frutos apresentaram-se com tingimento, nas concentrações de 2 e $4 \%$ para calda bordalesa, com percentuais de tingimento de $22,6 \%$ e $30,0 \%$, respectivamente. Para calda sulfocálcica esse dano foi menor em comparação a calda bordalesa, mas mesmo assim, com valores de $13,3 \%$ e $18,3 \%$, para as concentrações de 2 e $4 \%$, respectivamente. $\mathrm{O}$ fato de $100 \%$ dos frutos não apresentarem sintomas de tingimento, pode ser devido aos frutos tingidos estarem com o estádio de maturação próximo à colheita, no momento da aplicação. Desta forma, esse fator restringiu a aplicação das caldas em concentrações acima de 
$1 \%$, no experimento realizado em 2008, mesmo apresentando resultados de produtividade mais elevada em concentrações maiores. O tingimento dos frutos por produtos químicos é um fator de depreciação comercial, pois visualmente descaracteriza-os, além de apresentar a conotação de produto contaminado com agrotóxico.

Figura 1. Produção por planta (A), massa média dos frutos (B) e número de frutos (C) de morangueiro Cv. Camarosa em função dos tratamentos com calda bordalesa, calda sulfocálcica e biofertilizante supermagro. Dois Vizinhos, PR, 2007.

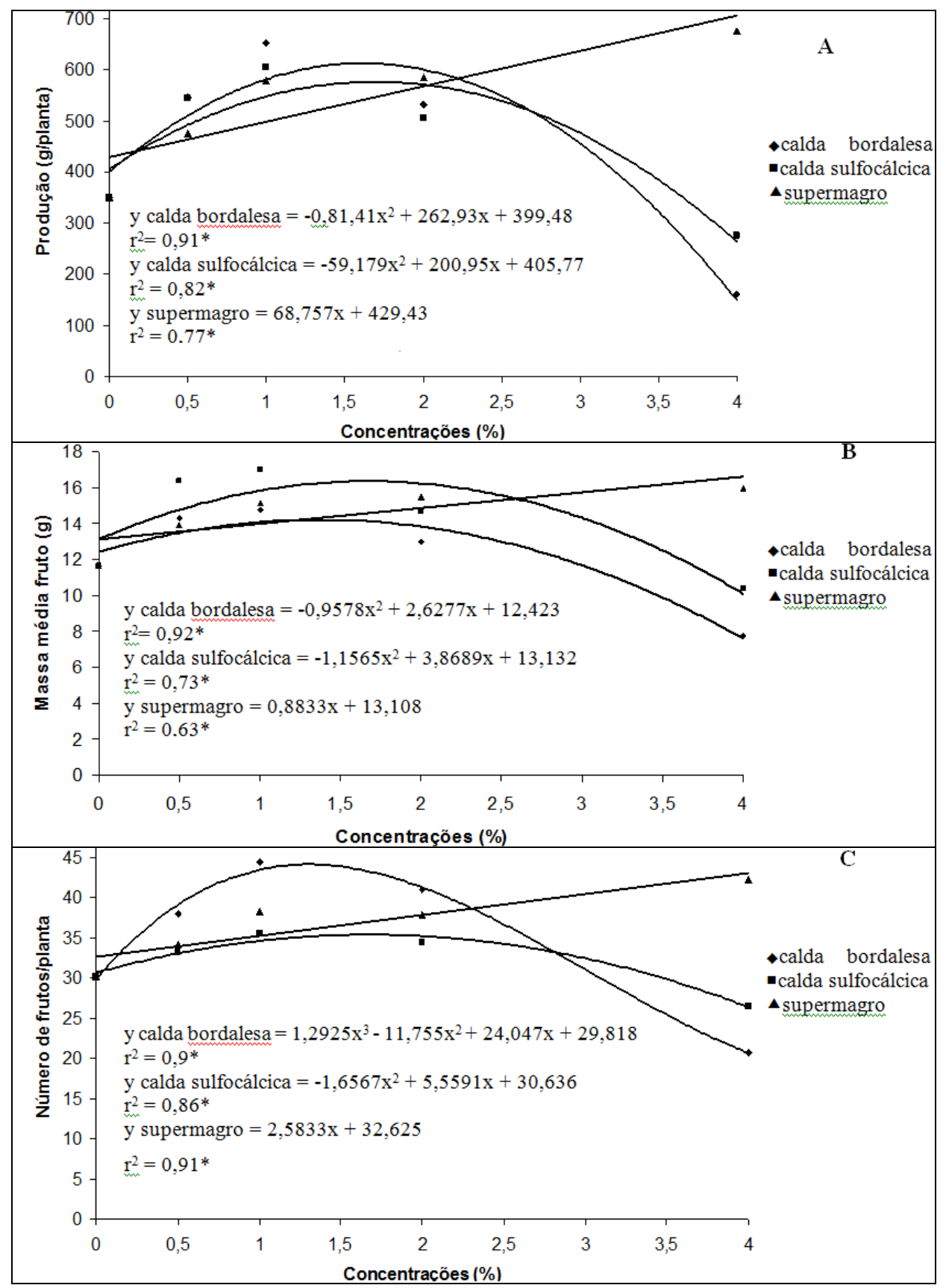

Fonte: Elaboração dos autores. 
Não foi observada diferença significativa para a área abaixo da curva de progresso da doença (AACPD) quanto à incidência das doenças avaliadas, em função dos tratamentos a que as plantas foram submetidas. No entanto, a severidade de micosferela foi reduzida pelo uso das caldas e do biofertilizante, independentemente da concentração utilizada (Tabela 1).

Tabela 1. Área abaixo da curva de progresso da doença (AACPD) para incidência e severidade de mancha-demicosferela, incidência de mancha-de-dendrofoma e incidência de antracnose (pecíolo foliar, no fruto e na flor) em plantas de morangueiro cultivar Camarosa não tratadas e tratadas com calda bordalesa, sulfocálcica e biofertilizante supermagro. Dois Vizinhos, PR, 2007.

\begin{tabular}{lcccc}
\hline \multirow{2}{*}{ Tratamentos } & \multicolumn{4}{c}{ AACPD } \\
\cline { 2 - 4 } & \multicolumn{2}{c}{ Mancha-de-micosferela } & $\begin{array}{c}\text { Mancha-de- } \\
\text { dendrofoma }\end{array}$ & Antracnose \\
\cline { 2 - 4 } & Incidência & Severidade & Incidência & Incidência \\
\hline Testemunha & $968,6 \mathrm{~ns}$ & $190,5 \mathrm{a}$ & $423,3 \mathrm{~ns}$ & $213,2 \mathrm{~ns}$ \\
Calda bordalesa 0,5\% & 876,4 & $67,0 \mathrm{~b}$ & 412,6 & 234,4 \\
Calda bordalesa 1\% & 934,8 & $69,9 \mathrm{~b}$ & 398,8 & 216,5 \\
Calda bordalesa 2\% & 879,6 & $71,8 \mathrm{~b}$ & 402,6 & 231,3 \\
Calda bordalesa 4\% & 903,6 & $69,1 \mathrm{~b}$ & 420,5 & 224,1 \\
Calda sulfocálcica 0,5\% & 895,4 & $65,6 \mathrm{~b}$ & 407,6 & 221,5 \\
Calda sulfocálcica 1\% & 916,8 & $65,8 \mathrm{~b}$ & 389,6 & 232,8 \\
Calda sulfocálcica 2\% & 922,8 & $66,8 \mathrm{~b}$ & 402,7 & 222,5 \\
Calda sulfocálcica 4\% & 912,6 & $67,0 \mathrm{~b}$ & 400,5 & 209,6 \\
Supermagro 0,5\% & 899,4 & $62,9 \mathrm{~b}$ & 398,6 & 217,4 \\
Supermagro 1\% & 912,4 & $64,3 \mathrm{~b}$ & 400,4 & 229,5 \\
Supermagro 2\% $\%$ & $68,8 \mathrm{~b}$ & 407,4 & 227,6 \\
Supermagro 4\% & 945,2 & $65,8 \mathrm{~b}$ & 389,6 & 239,6 \\
C.V\%. & 898,9 & $22,9 \mathrm{~b}$ & 56,8 & 24,7 \\
\hline
\end{tabular}

* Médias seguidas pela mesma letra na coluna não diferem pelo teste de Tukey $(P \leq 0,05)$.

Fonte: Elaboração dos autores.

Tais resultados, demonstraram uma tendência do efeito benéfico na redução de doenças pelo uso de caldas, e são confirmados por diversos trabalhos como os desenvolvidos por Theisen, Panzenhage e Koller (2006), na redução do cancro cítrico em plantas tratadas com calda bordalesa; os apresentados por Negri (2007) com a redução de podridão parda em pessegueiro pelo uso de calda sulfocálcica; e os obtidos por Miranda (2007), na redução de ferrugem e da cercosporiose em cafeeiros pelo uso de biofertilizante supermagro.

\section{Experimento 2-Ano 2008}

No experimento de 2008, a utilização das caldas proporcionou um incremento do número de frutos nas cultivares Camino Real e Camarosa em comparação com a testemunha (Tabela 2). Observou-se ainda que na cultivar Camarosa a aplicação feita com a alternância de produtos apresentou resposta superior a aplicação da calda bordalesa isolada, porém não diferiu da aplicação isolada de calda sulfocálcica e do biofertilizante supermagro. A cultivar Albion não apresentou diferença significativa em relação ao número de frutos em função da aplicação das caldas. 
Tabela 2. Número de frutos, produtividade e massa media de morangos cvs. Camarosa, Camino Real e Albion não tratadas e tratadas com calda bordalesa (1\%), sulfocálcica (1\%), biofertilizante supermagro (4\%) e alternância desses produtos. UTFPR - Dois Vizinhos, PR, 2008.

\begin{tabular}{|c|c|c|c|c|}
\hline \multirow{2}{*}{ CALDAS } & \multicolumn{3}{|c|}{ Cultivares } & \multirow[b]{2}{*}{ Médias } \\
\hline & Albion & Camarosa & Camino Real & \\
\hline \multicolumn{5}{|c|}{ Número de Frutos } \\
\hline $\mathrm{CB}$ & $25,25 \mathrm{~A} \mathrm{~b}$ & $31,75 \mathrm{~B} \mathrm{a}$ & $25,75 \mathrm{Ab}$ & 27,58 \\
\hline $\mathrm{CS}$ & $23,75 \mathrm{~A} \mathrm{~b}$ & $33,50 \mathrm{AB}$ a & $27,75 \mathrm{Ab}$ & 28,33 \\
\hline SM & $24,75 \mathrm{~A} \mathrm{~b}$ & $32,00 \mathrm{AB}$ a & $26,50 \mathrm{~A} \mathrm{~b}$ & 27,75 \\
\hline ALT & $26,00 \mathrm{~A} \mathrm{~b}$ & $35,00 \mathrm{~A} \mathrm{a}$ & $28,00 \mathrm{~A} \mathrm{~b}$ & 29,67 \\
\hline TEST & $23,25 \mathrm{~A} \mathrm{~b}$ & $24,75 \mathrm{C} \mathrm{a}$ & $21,25 \mathrm{~B} \mathrm{c}$ & 23,08 \\
\hline Médias & 24,60 & 31,40 & 25,85 & \\
\hline \multicolumn{5}{|c|}{ Produção (g planta) } \\
\hline $\mathrm{CB}$ & $338,75 \mathrm{~B} \mathrm{c}$ & $448,25 \mathrm{~A} \mathrm{a}$ & $401,25 \mathrm{~A} \mathrm{~b}$ & 396,08 \\
\hline $\mathrm{CS}$ & $319,50 \mathrm{Cc}$ & $469,00 \mathrm{~A} \mathrm{a}$ & $422,75 \mathrm{~A} \mathrm{ab}$ & 403,75 \\
\hline SM & $372,50 \mathrm{AB} b$ & $463,00 \mathrm{~A} \mathrm{a}$ & $393,75 \mathrm{~A} \mathrm{~b}$ & 409,75 \\
\hline ALT & $386,50 \mathrm{~A} \mathrm{c}$ & $492,75 \mathrm{~A} \mathrm{a}$ & $426,00 \mathrm{~A} \mathrm{~b}$ & 435,08 \\
\hline TEST & $322,50 \mathrm{C} \mathrm{a}$ & $348,75 \mathrm{~B} \mathrm{a}$ & $322,50 \mathrm{~B} \mathrm{a}$ & 329,50 \\
\hline Médias & 347,95 & 444,35 & 392,20 & \\
\hline \multicolumn{5}{|c|}{ Massa média (g) } \\
\hline $\mathrm{CB}$ & $13,55 \mathrm{~B} \mathrm{~b}$ & $13,95 \mathrm{~A} \mathrm{~b}$ & $15,15 \mathrm{~A} \mathrm{a}$ & 14,22 \\
\hline $\mathrm{CS}$ & $13,15 \mathrm{~B} \mathrm{~b}$ & $13,95 \mathrm{~A} \mathrm{ab}$ & $14,68 \mathrm{~A} \mathrm{a}$ & 13,93 \\
\hline SM & $14,60 \mathrm{~A} \mathrm{a}$ & $14,38 \mathrm{~A} \mathrm{a}$ & $15,00 \mathrm{~A} \mathrm{a}$ & 14,66 \\
\hline ALT & $14,78 \mathrm{~A} a b$ & $14,03 \mathrm{~A} \mathrm{~b}$ & $15,28 \mathrm{~A} \mathrm{a}$ & 14,69 \\
\hline TEST & $13,23 \mathrm{~B} \mathrm{c}$ & $14,15 \mathrm{~A} \mathrm{~b}$ & $15,15 \mathrm{~A} \mathrm{a}$ & 14,18 \\
\hline Médias & 13,86 & 14,09 & 15,05 & \\
\hline
\end{tabular}

*Médias seguidas pelas mesmas letras minúsculas, na linha, e maiúsculas, na coluna, não diferem significativamente entre si pelo Teste de Tukey $(P \leq 0,005)$. ALT - alternância de aplicação de caldas bordalesa, sulfocálcica e biofertilizante supermagro; SM biofertilizante supermagron; CS - calda sulfocálcica; CB - calda bordalesa; TES - testemunha.

Fonte: Elaboração dos autores.

As cultivares Camino Real e Camarosa aumentaram a produção por planta nos tratamentos em que foram aplicadas as caldas, isoladas ou em alternância (Tabela 2). Para a cultivar Albion a alternância de caldas apresentou resposta superior aos demais tratamentos não diferindo significativamente do biofertilizante supermagro. Nessa cultivar, não se observou o efeito benéfico da aplicação da calda sulfocálcia de forma isolada. De maneira geral, esses resultados, reforçam o que foi observado no experimento anterior, demonstrando o efeito benéfico do uso das caldas e biofertilizantes no incremento da produtividade de morangueiros.

A massa média de frutos para a cultivar Camino Real e Camarosa não apresentou diferença significativa em relação aos tratamentos utilizados (Tabela 2). A cultivar Albion apresentou resposta superior para massa média de frutos com a aplicação do biofertilizante supermagro e a alternância de caldas. Santos et al. (2007), quando fizeram uso de calda bordalesa, verificaram aumento de produtividade e número de frutos por planta na cultura do maracujazeiro.

A aplicação de caldas bordalesa e sulfocálcica e do biofertilizante supermagro, isolados ou em alternância, não alteraram os teores sólidos solúveis totais e acidez titulável, confirmando os resultados obtidos no experimento anterior. As médias de acidez titulável foram de 9,53; 10,93 e 10,64 gramas de ácido cítrico/100 mL, para Albion, 
Camarosa e Camino Real, respectivamente. Já os teores de sólidos solúveis totais foram de 5,77; 6,11 e 6,21 ${ }^{\circ}$ Brix para Camino Real, Camarosa e Albion, respectivamente.

Pelos resultados observados quanto à incidência de mancha-de-micosferela e de mancha-de- dendrofoma, pode-se observar que não ocorreu resposta significativa para os tratamentos utilizados, porém as cultivares Camarosa e Albion apresentaram maior incidência dessas doenças que a cultivar Camino Real (Tabela 3 ).

Tabela 3. Área abaixo da curva de progresso de doenças (AACPD) para incidência de Micosferela e Manchade-dendrofoma em plantas de morangueiro não tratadas e tratadas com calda bordalesa (1\%), sulfocálcica (1\%), biofertilizante supermagro (4\%) e alternância desses produtos. UTFPR -Dois Vizinhos, PR, 2008.

\begin{tabular}{lll}
\hline AACPD & Micosferela & Dendrofoma \\
\hline Cultivares & Médias & Médias \\
\hline Camino Real & $144,88 \mathrm{~b}$ & $61,89 \mathrm{~b}$ \\
Camarosa & $966,04 \mathrm{a}$ & $431,13 \mathrm{a}$ \\
Albion & $969,84 \mathrm{a}$ & $498,47 \mathrm{a}$ \\
\hline Médias & 707,27 & 337,77 \\
\hline CV $(\%)$ & 92,62 & 56,61 \\
\hline Caldas & Médias & Médias \\
\hline CB & $314,80^{\text {ns }}$ & $253,63^{\text {ns }}$ \\
CS & 574,45 & 296,93 \\
SM & 819,51 & 334,56 \\
ALT & 890,73 & 350,70 \\
TEST & 936,87 & 453,05 \\
\hline Média & 707,27 & 337,77 \\
\hline CV $(\%)$ & 53,47 & 56,61 \\
\hline
\end{tabular}

* Médias seguidas de letras distintas na coluna diferem significativamente entre si pelo teste de Tukey $(P \leq 0,005) .{ }^{\text {ns }}$ Não significativo. ALT - alternância de aplicação de caldas bordalesa, sulfocálcica e biofertilizante supermagro; SM - biofertilizante supermagro; CS - calda sulfocálcica; CB - calda bordalesa; TES - testemunha.

Fonte: Elaboração dos autores.

Já para a severidade da mancha-de-micosferela (Tabela 4) na cultivar Camarosa, todos os tratamentos reduziram a severidade da doença em comparação com a testemunha. Na 'Camino Real' a aplicação de calda sulfocálcica apresentou melhor resultado, não diferindo da calda bordalesa e na cultivar Albion não ocorreu diferença significativa.

Tais dados vêm confirmar os obtidos no experimento do ano anterior, não ocorrendo interferência dos tratamentos na incidência das doenças, e sim na redução da severidade das mesmas. Pode-se observar que a cultivar Camino Real em comparação com a Camarosa e Albion é mais resistente as doenças avaliadas, fato demonstrado pela menor incidência das mesmas. O efeito das caldas pode apresentar variação entre cultivares, condições ambientais e de manejo, fato observado nesse trabalho. 
Tabela 4. Área abaixo da curva de progresso de doenças (AACPD) para severidade de mancha-de-micosferela em plantas de morangueiro não tratadas e tratadas com calda bordalesa (1\%), sulfocálcica (1\%), biofertilizante supermagro (4\%) e alternância desses produtos. UTFPR -Dois Vizinhos,PR, 2008.

\begin{tabular}{lllll}
\hline \multicolumn{4}{c}{ AACPD } \\
\cline { 2 - 4 } CALDAS & \multicolumn{4}{c}{ CULTIVARES } \\
CB & Albion & Camarosa & Camino Real & Médias \\
CS & $87,41 \mathrm{~A} \mathrm{a}$ & $80,31 \mathrm{~B} \mathrm{a}$ & $111,71 \mathrm{AB}$ a & 93,14 \\
SM & $16,46 \mathrm{~A} \mathrm{a}$ & $61,59 \mathrm{~B} \mathrm{a}$ & $48,84 \mathrm{~B} \mathrm{a}$ & 42,30 \\
ALT & $41,14 \mathrm{~A} \mathrm{ab}$ & $179,66 \mathrm{~B} \mathrm{ab}$ & $346,66 \mathrm{~A} \mathrm{a}$ & 189,15 \\
TEST & $19,08 \mathrm{~A} \mathrm{a}$ & $252,42 \mathrm{~B} \mathrm{ab}$ & $285,61 \mathrm{Aa}$ & 185,70 \\
Médias & $13,46 \mathrm{~A} \mathrm{~b}$ & $534,96 \mathrm{~A} \mathrm{a}$ & $233,13 \mathrm{~A} \mathrm{a}$ & 303,97 \\
\hline CV(\%) & 36,67 & 236,70 & 205,19 & \\
\hline
\end{tabular}

*Médias seguidas pelas mesmas letras minúsculas, na linha, e maiúsculas, na coluna, não diferem significativamente entre si pelo Teste de Tukey $(P \leq 0,005)$. ALT - alternância de aplicação de caldas bordalesa, sulfocálcica e biofertilizante supermagro; SM biofertilizante supermagro; CS - calda sulfocálcica; CB - calda bordalesa; TES - testemunha

Fonte: Elaboração dos autores.

Conforme Coelho (2009), os fungicidas cúpricos como a calda bordalesa e o oxicloreto de cobre continuam a ser utilizados de forma simples ou em combinação com fungicidas para controlar alguns patógenos em diversas culturas, tais como: a $P$. viticola, na videira; a Phytophthora infestans, na batata e no tomate; a Pseudoperenospora humuli, no lúpulo; a Mycosphaerella musicola, na banana; o Colletotrichum kahawae, no café; e Exobasidium vexans, no chá.

Baptista, Resende e Oliveira (2007), em experimento em casa de vegetação, verificaram que a calda bordalesa apresentou controle eficiente da pinta preta (Alternaria solani) do tomateiro. Nos experimentos realizados no campo, em sistema orgânico de produção, os autores não verificaram efeito dos tratamentos devido à baixa severidade da doença.

Com os resultados obtidos nos dois experimentos, pode-se concluir que as caldas bordalesa e sulfocálcica, bem como o biofertilizante supermagro interferem positivamente no número de frutos, massa média e produção do morangueiro. Concentrações acima de 1,0\% de calda bordalesa e sulfocálcica, causam manchamento nos frutos, enquanto o biofertilizante supermagro não apresenta restrição de concentração para esse efeito, apresentando respostas positivas ao aumento das concentrações até 4\%.

Os teores de acidez titulável, sólidos solúveis totais não são influenciados pelos tratamentos com calda bordalesa, calda sulfocálcica e biofertilizante supermagro.

A aplicação das caldas e do biofertilizante supermagro interferem no controle de doenças com um efeito benéfico na redução da severidade da mancha-de-micosferela na cultivar Camarosa e uma tendência na cultivar Camino Real com a utilização da calda bordalesa e sulfocálcica.

\section{Referências}

ANDRADE, D. J.; PATARRO, F. C.; OLIVEIRA, C. A. L. Resíduos de calda sulfocálcica sobre a eficiência de acaricidas no controle de Brevipalpus phoenici. Revista Ciência Rural, Santa Maria, v. 41, n. 10, p. 1695-1701, 2011.

BAPTISTA, M. J.; RESENDE, F. V.; OLIVEIRA, A. R. Avaliação de produtos alternativos no manejo da pinta preta do tomateiro. Revista Brasileira de Agroecologia, Brasília, v. 2, n. 2, p. 694-697, 2007.

BURG, I. C.; MAYER, P. H. Alternativas ecológicas para prevenção e controle de pragas e doenças. Francisco Beltrão: Grafit/Assesoar, 2002. 153 p.. 
CAMPBELL, C. L.; MADDEN, L. V. Introduction to plant disease epidemiology. New York: John Wiley, 1990. $532 \mathrm{p}$.

COELHO, V. P. Efeito do fosfonato de potássio na protecção das raízes do castanheiro (Castanea sativa Mill.) contra Phytophthora cinnamomi. 2009. Dissertação (Mestrado em Agroecologia) - Instituto Politécnico de Bragança. Escola Superior Agrária, Bragança.

GÓES, A.; MARTINS, R. D.; REIS, R. F. Efeito de fungicidas cúpricos, aplicados isoladamente ou em combinação com mancozeb, na expressão de sintomas de fitotoxicidade e controle da ferrugem causada por Puccinia psidii em goiabeira. Revista Brasileira de Fruticultura, Jaboticabal, v. 26, n. 2, p. 237-240, 2004.

MAZARO. S. M.; DESCHAMPS, C.; MAY-DE-MIO, L. L.; BIASI, L. A; GOUVEA, A. SAUTTER, C. K. Comportamento pós-colheita de frutos de morangueiro após a aplicação pré-colheita de quitosana e acibenzolarsmetil, Revista Brasileira Fruticultura, Jaboticabal, v. 30, n. 1, p. 185-190, 2008.

MAZARO, S. M.; GOUVEA, A.; MAY-DE-MIO, L. L.; DESCHAMPS, C.; BIASI, L. A; CITADIN, I. Escala diagramática para avaliação da severidade da manchade-micosferela em morangueiro. Revista Ciência Rural, Santa Maria, v. 36, n. 2, p. 648-652, 2006.

MESQUITA, E. F.; CAVALCANTE, L. F.; GONDIM, S. C.; CAVALCANTE, I. H. L.; ARAUJO, F. A. R.; BECKMANN-CAVALCANTE, M. Z. Produtividade e qualidade de frutos do mamoeiro em função de tipos e doses de Biofertilizantes. Revista Ciências Agrárias, Londrina, v. 28, n. 4, p. 589-596, 2007.

MIRANDA, J. C. Doenças em cultivo orgânico do cafeeiro (Coffea arabica L.): epidemiologia e controle alternativo. 2007. Tese (Doutorado em Fitopatologia) Universidade Federal de Lavras, Lavras.
NEGRI, G. Controle da podridão parda em pessegueiro conduzido em sistema orgânico e produção do antagonista Trichothecium roseum. 2007. Tese (Doutorado em Agronomia) - Universidade Federal do Paraná, Curitiba.

PERUCH, L. A. M.; BRUNA E. D. Relação entre doses de calda bordalesa e de fosfito potássico na intensidade do míldio e na produtividade da videira cv. 'Goethe'. Revista Ciência Rural, Santa Maria, v. 38, n. 9, p. 24132418, 2008.

RODRIGUES, A. C.; CAVALCANTE, L. F.; OLIVEIRA, A. P.; SOUZA, J. T.; MESQUITA, F. O. Produção e nutrição mineral do maracujazeiro-amarelo em solos com biofertilizante supermagro e potássio. Revista Brasileira de Engenharia Agrícola e Ambiental, Campina Grande, v. 13, n. 2, p. 117-124, 2009.

SANTOS, F. S.; LEMOS, J. N. R.; ALBUQUERQUE, I. C.; BRITO L. M. P. Produção de goiabeira e maracujazeiro utilizando alternativa orgânica. Tecnologia e Ciência Agropecuária, João Pessoa, v. 1, n. 1, p. 15-18, 2007.

TANAKA, M. A. S.; PASSOS, F. A. Caracterização patogênica de Colletotrichum acutatum e C. Fragariae associados à antracnose do morangueiro. Fitopatologia Brasileira, Brasília, v. 27, n. 5, p. 484-488. 2002.

THEISEN, S.; PANZENHAGE, N. V.; KOLLER, O. C. Calda bordalesa no controle de cancro citrico. Revista Brasileira de Agroecologia, Brasília, v. 1, n. 1, p. 939942, 2006.

VENZON, M.; ROSADO, M. C.; PINTO, C. M. F.; DUARTE, V. S.; EUZEBIO, D. E.; PALLINI, A. Potencial de defensivos alternativos para o controle de àcaro-branco em pimenta malagueta. Horticultura Brasileira. Brasília, v. 24, n. 2, p. 224-227, 2006. 